\title{
Traditional Gymnastic Exercises for the Pelvic Floor Often Lead to Bladder Neck Descent - a Study Using Perineal Ultrasound
}

\section{Traditionelle Beckenbodengymnastik führt häufig zum Blasenhals- deszensus - eine Untersuchung mit perinealem Ultraschall}

Authors

Kaven Baeßler, Bärbel Junginger

Affiliation

Campus Benjamin Franklin, Abt. für Gynäkologie,

Beckenbodenzentrum Charité, Berlin, Germany

Key words

pelvic floor training, pelvic floor rehabilitation, bladder neck, perineal ultrasound, pelvic floor contraction

Schlüsselwörter

Beckenbodengymnastik, Beckenbodenrehabilitation, Blasenhals, perinealer Ultraschall, Beckenbodenkontraktion

received $\quad 30.11 .2016$

revised 7.2.2017

accepted 10.2.2017

\section{Bibliography}

DOI http://dx.doi.org/10.1055/s-0043-103460

Published online 24. 5. 2017 | Geburtsh Frauenheilk 2017; 77 : 765-770 @ Georg Thieme Verlag KG Stuttgart · New York | ISSN 0016-5751

\section{Correspondence}

PD Dr. med. Kaven Baeßler

Campus Benjamin Franklin, Abt. für Gynäkologie,

Beckenbodenzentrum Charité

Hindenburgdamm 30, 12203 Berlin, Germany

kaven.baessler@charite.de

$\Theta$

Deutsche Version unter:

http://dx.doi.org/10.1055/s-0043-103460

\section{ABSTRACT}

Background The aims of physiotherapy in stress incontinent women are to improve pelvic floor function and the continence mechanism including bladder neck support and urethral closure pressure. In Germany, traditional conservative treatment often includes gymnastic exercises with unclear effects on the bladder neck. The aim of this study was to sonographically assess bladder neck movements during selected exercises.

Methods Fifteen healthy, continent women without previous vaginal births, who were able to voluntarily contract their pel- vic floor muscels performed the shoulder bridge, the abdominal press, tiptoe and the Pilates clam exercises. The first set was performed without any additional instructions. During the second set directions were given to activate the pelvic floor before beginning each exercise and to maintain the contraction throughout the exercise. Bladder neck movement was measured on perineal ultrasound using a validated method with the pubic symphysis as a reference point.

Results The median age of participants was 32 years, median $\mathrm{BMI}$ was 23. Eight women were nulliparous and seven had given birth to 1-2 children via caesarean section. When exercises were performed without voluntary pelvic floor contraction the bladder neck descended on average between 2.3 and $4.4 \mathrm{~mm}$, and with pelvic floor contraction prior to the exercise only between 0.5 and $2.1 \mathrm{~mm}$ ( $p>0.05$ except for abdominal press $p=0.007)$. The Pilates clam exercise and toe stand stabilised the bladder neck most effectively.

Discussion Bladder neck descent often occurs during pelvic floor gymnastic exercises as traditionally performed in Germany, and a voluntary pelvic floor contraction during the exercises does not necessarily prevent this.

\section{ZUSAMMENFASSUNG}

Hintergrund Das Ziel der physiotherapeutischen Behandlung der Belastungsinkontinenz ist die Verbesserung der Beckenbodenmuskulatur und damit des Kontinenzmechanismus, deren Hauptfaktoren die Blasenhalsstabilität und der urethrale Verschlussdruck sind. Die Beckenbodengymnastik in Deutschland beinhaltet häufig unspezifische gymnastische Übungen, deren Wirkungen auf Beckenboden und Blasenhals nicht geklärt sind. Das Ziel dieser Studie ist es, perineal-sonografisch zu untersuchen, welche Auswirkungen ausgewählte Beckenbodenübungen auf die Blasenhalsposition haben.

Methoden Fünfzehn gesunde kontinente Frauen ohne vaginale Geburten, die den Beckenboden willkürlich anspannen konnten, führten Schulterbrücke, Bauchpresse, Zehenspitzenstand und Pilates-Muschelübung aus. Eine 1. Übungsserie erfolgte ohne Hinweise zum Beckenboden, die 2. mit Anleitung zur Beckenbodenkontraktion vor und während der Übung. Mittels perinealem Ultraschall wurden die Blasenhalsbewegungen mit einem validierten Verfahren mit der Symphyse als Referenzpunkt ausgemessen.

Ergebnisse Die Frauen waren im Median 32 Jahre alt und hatten einen medianen BMI von 23. Acht Frauen waren nullipar, 7 hatten 1-2 Kinder via Sectio caesarea geboren. Während der Übungen ohne willkürliche Beckenbodenkontraktion des- 
zendierte der Blasenhals im Mittel zwischen 2,3 und 4,4 mm; mit Beckenbodenkontraktion vor der Übung nur zwischen 0,5 und 2,1 mm ( $p>0,05$ bis auf Bauchpresse $p=0,007)$. Die Pilates-Muschelübung und der Zehenspitzenstand stabilisierten den Blasenhals am besten.
Diskussion Bei Übungen der traditionellen deutschen Beckenbodengymnastik deszendiert der Blasenhals häufig und kann nicht immer durch eine willkürliche Beckenbodenkontraktion vor der Übung stabilisiert werden.

\section{Introduction}

Urethral closing pressure, precontraction of the pelvic floor and bladder neck stability are factors that ensure urinary continence [1-4]. It is known that the bladder neck (BN) descends further on coughing in women with stress urinary incontinence compared to continent women [5]. In contrast, correct pelvic floor contraction (PFC) elevates the bladder and bladder neck (ventro-cranial movement) [5-8]. The bladder neck is stabilised and descends significantly less if PFC is performed before and maintained during coughing [9]. Both bladder neck descent and elevation can be well documented on two-dimensional perineal ultrasound and can be quantified using validated methods $[7,8,10]$.

Pelvic floor contraction before coughing or other exertions that cause an increase in intraabdominal pressure has been termed "The Knack" or pelvic floor precontraction [11]. Learning this skill is part of modern pelvic floor rehabilitation and is specifically taught in international programs [11-14]. However traditional pelvic gymnastics training in Germany is mostly comprised of nonspecific exercises. In healthy women these nonspecific exercises may lead to pelvic floor contraction through coactivation of abdominal or gluteal and pelvic floor muscles [15-17], however it is not known whether the desired bladder neck elevation or at least stabilisation is achieved. In addition, this automatic co-contraction can only be expected in healthy subjects [17] and not in incontinent women: In healthy, continent women pelvic floor precontraction occurs before a potentially destabilising activity and/ or actions leading to increased intraabdominal pressure. In contrast, this precontraction may be lost in incontinent women [1821]. There are no data on the efficacy of traditional pelvic floor gymnastics as currently performed in Germany.

The pelvic floor is increasingly being integrated into yoga and Pilates programs, which are offered for both treatment and prophylaxis. The fact that $20-43 \%$ of women cannot tighten their pelvic floor musculature on command, or worse even bear down [22-24], is not sufficiently taken into consideration by fitness or traditional pelvic floor gymnastic programs on offer.

The aim of this study was to determine the position of the bladder neck using perineal ultrasound during selected exercises from traditional German pelvic floor gymnastic exercises and Pilates in healthy women.

\section{Materials and Methods}

\section{Subjects, inclusion and exclusion criteria}

Fifteen healthy women without pelvic floor symptoms (screening using a validated pelvic floor questionnaire) [25] and no previous vaginal births or urogynaecological operations were consecutively recruited via notice boards and informational events. All women gave written, informed consent. The measurements were part of a multilevel DFG (German Research Foundation) funded project that was approved by the Charité ethics commission. Women with previous vaginal births were excluded, since vaginal birth may lead to permanently altered bladder neck position $[6,26]$, and the effects of levator avulsion (muscle disruption from the inferior pubic rami), which occurs commonly, are uncertain [27]. The ability to voluntarily contract the pelvic floor musculature was a further inclusion criterion and was tested by palpation and perineal ultrasound. All examinations were performed by the same investigator (BJ) at a bladder volume of 150 to $300 \mathrm{ml}$ for optimal visualisation of the bladder neck [10] without subjects having an urge to urinate.

\section{Exercises}

Study subjects performed the following exercises, all of which are possible with simultaneous application of the perineal ultrasound probe (abdominal probe) ( $\vee$ Fig. 1 ): the shoulder bridge, the abdominal press, tiptoe and the Pilates clam exercise. The first set of exercises was performed without any instructions regarding the pelvic floor. For the second set, women were instructed to voluntarily contract their pelvic floor muscles prior to starting each exercise (pelvic floor precontraction $=$ PF-preC) and to maintain the contraction throughout each exercise. A physiotherapist with Pilates experience gave the instructions. Each exercise lastet for 3-7 seconds. We purposely omited repetitions when the quality of the measurement was deemed satisfactory. There were not more than three repetitions to improve study quality for any of the exercises. Averages were not calculated.

\section{Ultrasound measurements}

Bladder neck movements during the exercises were recorded on perineal ultrasound (abdominal probe RAB 4-8-D, $5 \mathrm{MHz}$, Voluson E8, GE) and saved as videos in a computer program (Tele Myo "Human performance measurements solutions" MR 3.0; Noraxon USA Inc). The analysis was conducted offline by one investigator (KB) using a validated digital tracking system [28]. Standardisation was performed according to Dietz with the distal pole of the pubic symphysis used as the reference point for both the $x$ and $y$-axis [29]. A prerequisite for this is that the ultrasound probe 

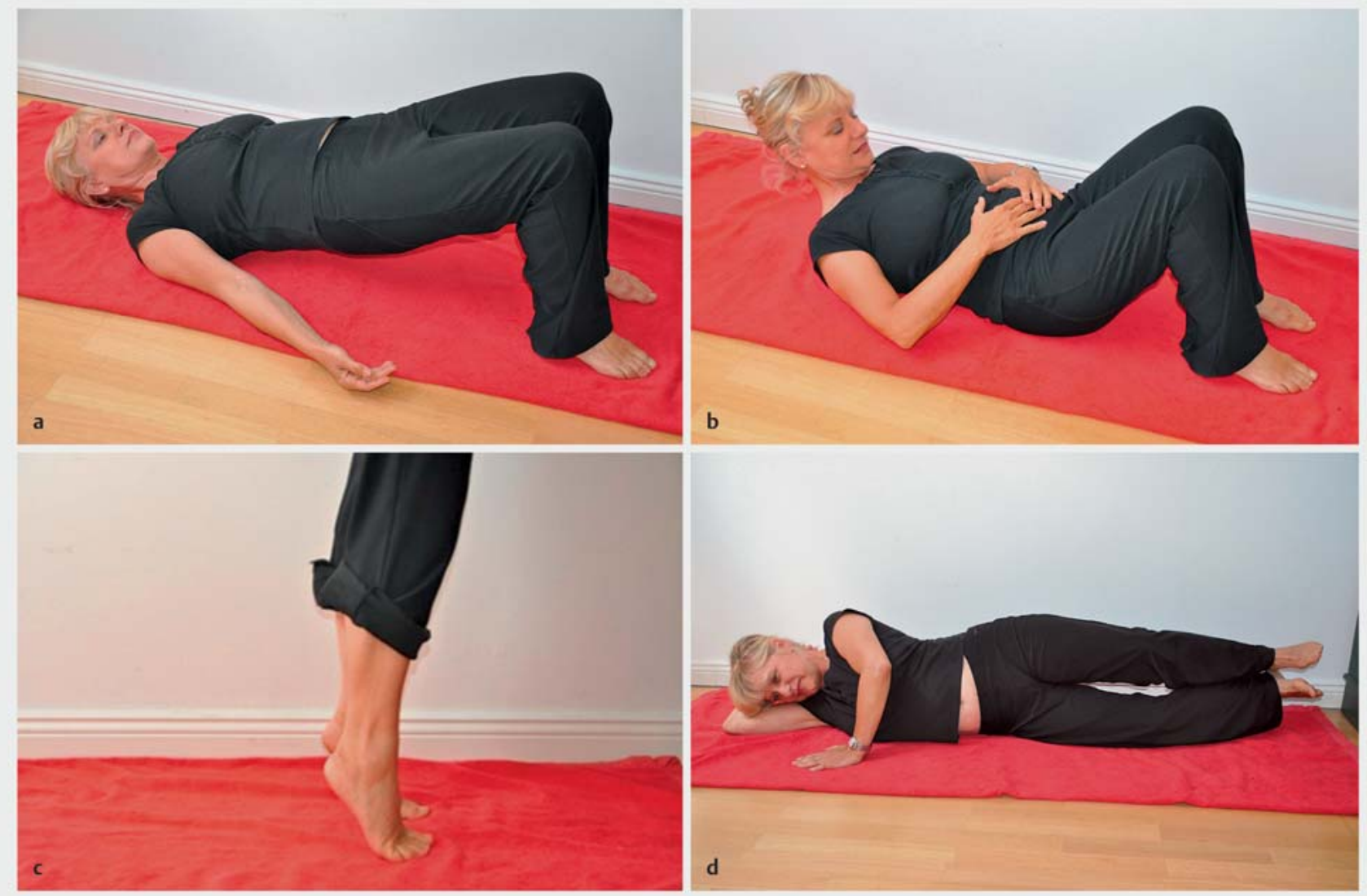

- Fig. 1 Study exercises: shoulder bridge (a), abdominal press (b), standing on tiptoe (c) and Pilates clamshell (d).

with its outgoing cable remain strictly in line with the body axis since changes in the tilt angle would result in false measurements [30] ( Fig. 2). Visible "shifting" of the symphysis, e.g. through increased intraabdominal pressure during an exercise, was corrected in analogy to the validation according to Reddy et al. [28]. The minimal detectible change in bladder neck movement on perineal ultrasound was established at $3 \mathrm{~mm}$ [7].

\section{Analysis}

All acquired data were analysed using the statistics program SPSS 22. Paired t-tests were used to compare bladder neck movements between exercises for normally distributed variables.

\section{Results}

\section{Study subjects}

Participants were aged between 21 and 45 years (median 32 years) with a median BMI of $23\left(18-31 \mathrm{~kg} / \mathrm{m}^{2}\right)$. Eight women were nulliparous and seven had given birth to one or two children via caesarean section. All women were able to perform bladder neck elevating pelvic floor contractions that were palpable and demonstrable on ultrasound.

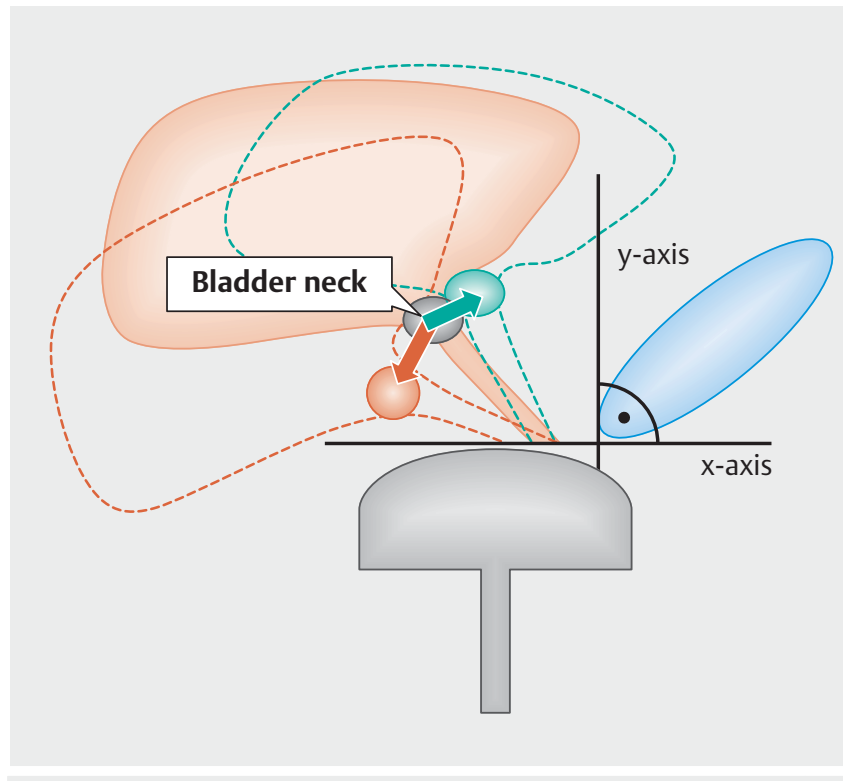

- Fig. 2 Schematic depiction of the bladder neck, the coordination system and correct application of the ultrasound probe. Typical position during bladder neck descent (red) and bladder neck elevation (green). 

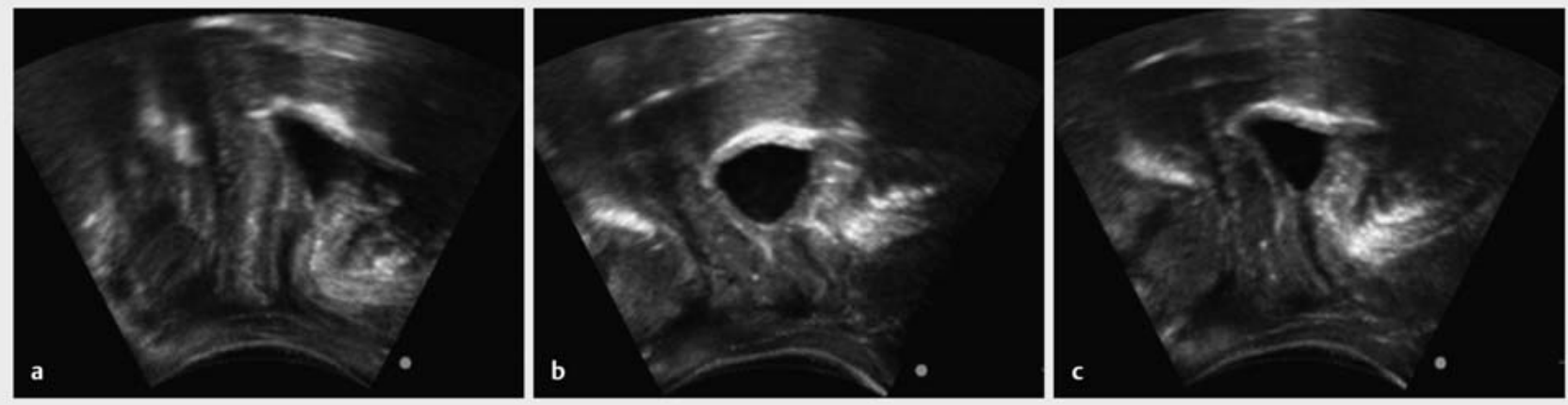

- Fig. 3 Typical perineal ultrasound images before, during and after the shoulder bridge exercise from a woman with significant BN descent: a at rest, b obvious bladder neck descent during the exercise, $\mathrm{c}$ almost complete return to normal position after exertion.

\section{Exercises without pelvic floor precontraction}

Results are summarised in $>$ Table $\mathbf{1}$. Bladder neck (BN) movement during the exercises was highly variable and not identical among all women for any of the exercises. When performed without voluntary pelvic floor precontraction all exercises were associated with BN descent between 2.3 and $4.4 \mathrm{~mm}$ on average. In contrast to the shoulder bridge and abdominal press (BN descent -3.2 and $-4.4 \mathrm{~mm}$ respectively), the Pilates clam and tiptoe exercise stabilised the bladder neck best $(-2.3$ and $-2.6 \mathrm{~mm}$ respectively), however, differences between individual exercises were not statistically significant. - Fig. $\mathbf{3}$ a to $\mathbf{c}$ shows the typical progression of bladder neck descent on perineal ultrasound in a woman with $\mathrm{BN}$ descent during the exercise.

\section{Exercises with pelvic floor precontraction}

Pelvic floor contraction prior to the exercises temporarily elevated the bladder neck in all women, however there was subsequent BN descent of 0.5 to $2.1 \mathrm{~mm}$ on average during execution of the shoulder bridge, the abdominal press and, to the smallest amount, the clam exercise. The original BN elevation of $2.7 \mathrm{~mm}$ was maintained while standing on tiptoe, though there were no statistically significant differences between the exercises. - Fig. 4 a to c shows an example of stable BN position with the pelvic floor contraction maintained for the entire duration of an exercise.

\section{Comparison of bladder neck descent for exercises with and without pelvic floor precontraction}

There was less BN descent for exercises with PF precontraction than without, however the difference was only statistically significant for the abdominal press $(p=0.007)$.

\section{Discussion}

This study in a small number of healthy, continent women shows that traditional gymnastic exercises for the pelvic floor do not necessarily stabilise or elevate the bladder neck. This also applies when women contracted their pelvic floor muscles - with bladder neck elevation demonstrated on ultrasound - prior to performing the exercises. Although a specific pelvic floor contraction initially lead to BN elevation in all the women, this bladder neck position was rarely maintained for the entire duration of the exercise. The Pilates clam exercise and standing on tiptoe achieved the best bladder neck stabilisation. BN descent was most marked with the abdominal press, however a voluntary pelvic floor precontraction significantly reduced this descent.

Our study subjects were all able to evidently contract their pelvic floor muscles on command. However, this ability can neither be assumed for all healthy women, nor for incontinent women. A significant proportion of incontinent women is not able to contract their pelvic floor muscles [22-24] and physiological pelvic floor precontraction is not always present [19]. Our results imply

- Table 1 Average bladder neck descent in mm (standard deviation) for series of exercises without and then with pelvic floor precontraction (PF-preC). Negative values represent bladder neck descent, positive values bladder neck elevation. Paired t-test for comparison.

\begin{tabular}{|l|l|l|l|}
\hline & Without PF-preC & With PF-preC & P \\
\hline Shoulder bridge & $-3.2(2.8)$ & $-2.1(4.8)$ & 0.574 \\
\hline Abdominal press & $-4.4(1.9)$ & $-2.2(4.2)$ & 0.007 \\
\hline Tiptoe & $-2.3(3.9)$ & $2.7(3.2)$ & 0.086 \\
\hline Clam & $-2.6(1.9)$ & $-0.5(4.8)$ & 0.580 \\
\hline
\end{tabular}



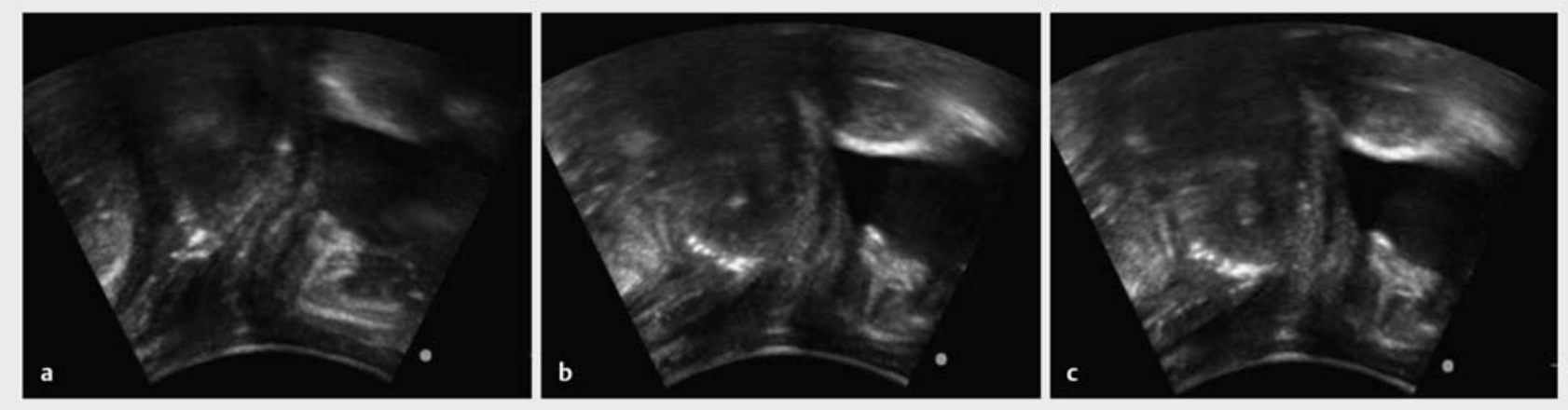

- Fig. 4 Typical perineal ultrasound images of a woman able to stabilise the BN for the duration of the shoulder bridge exercise: a at rest, b pelvic floor precontraction prior to exercise causes BN elevation, $c$ bladder neck stabilised with elevation held until exercise end.

that the studied exercises can not provide the desired effects for many incontinent women, since not all physiotherapists (or gynaecologists) in Germany test the status of the pelvic floor musculature by palpation e.g. before physiotherapy. It can be presumed that in many women with pelvic floor disorders the bladder and urethra descend even further during these traditional exercises, especially when women are unable to voluntarily tighten their pelvic floor muscles. Although gymnastic exercises and $\mathrm{Pi}$ lates or yoga certainly can achieve a coactivation of the pelvic floor, this does not automatically translate into BN elevation or stabilisation. Also, the principles of the actually intended muscle training are neglected: specificity, overload and reversibility [31]. The first of these involves specific contraction of the pelvic floor, which internationally is most often assessed on vaginal palpation by the therapist. The second, overload, is achieved through purspecific contractions at a much higher intensity than the involuntary contractions occurring in day-to-day life e.g. through co-contraction. The third characteristic of a muscle training program, reversibility, shows up the limitations of an otherwise internationally successful pelvic floor training program based on increasing the muscle strength [32]. Physiotherapy studies that increase pelvic floor muscle strength attribute decreasing continence rates after a number of years to reduced adherence and discontinuation of training. It is currently being investigated whether a pelvic floor rehabilitation program conceptually based specifically on coordination, BN elevation and pelvic floor integration into everyday life [13] could provide long-term success. From work on the multifidi muscles, which, like the pelvic floor, are predominantly composed of type 1 (slow-twitch) fibres, rehabilitation for back pain is known to be effective in the long-term without further training [33].

Stabilising the bladder neck, which is partly achieved by sufficient pelvic floor contraction, is essential for ensuring continence $[1,34,35]$. Perineal ultrasound allows good visualisation and quantification of bladder neck elevation and descent. It is thus suitable for use as a biofeedback instrument and is increasingly being used by physiotherapists for pelvic floor rehabilitation [8, 13,36-38]. Vaginal and/or rectal palpation do however appear to be essential for assessing the pelvic floor anatomically and functionally, enabling the development of individualised rehabili- tation programs. Pelvic floor palpation is currently not part of physiotherapy training in Germany and appropriate skills have to be acquired at palpation courses.

It can be assumed that bladder neck descent occurs during many other exercises and sports, especially among women with pelvic floor disorders. A comparative study on this subject is currently in progress. Further studies are needed to define physiological ranges, to investigate whether sport can worsen pelvic organ prolapse and whether e.g. pelvic floor precontraction before exertion or other bladder neck supporting measures such as pessaries can prevent pelvic organ prolapse.

Limitations of this study are the small number of study participants and the difficulty performing perineal ultrasound for all the study exercises. The minimal detectable change in bladder neck movement on perineal ultrasound is $3 \mathrm{~mm}$ [7], which was achieved in our study for most of the exercises. Strengths of the study are the use of validated measurement techniques including questionnaires and ultrasound assessment and interpretation. In addition, the acquisition of data from healthy women contributes to the establishment of normal values and the planning of future studies.

\section{Conclusion}

Traditional gymnastic exercises for the pelvic floor frequently lead to bladder neck descent in continent women. The bladder neck descends less when the pelvic floor is contracted prior to, and held for the duration of an exercise. Since the ability to voluntarily contract the pelvic floor cannot be generally assumed, the traditional gymnastic exercises for the pelvic floor in Germany without prior confirmation of correct pelvic floor contraction, should be abandoned.

\section{Conflict of Interest}

No conflicts of interest exist currently or in the past for either of the two authors. 


\section{References}

[1] DeLancey JO. Structural support of the urethra as it relates to stress urinary incontinence: the hammock hypothesis. Am J Obstet Gynecol 1994; 170: 1713-1720; discussion 1720-1723

[2] Delancey JO, Ashton-Miller JA. Pathophysiology of adult urinary incontinence. Gastroenterology 2004; 126: S23-S32

[3] DeLancey JO, Trowbridge ER, Miller JM et al. Stress urinary incontinence: relative importance of urethral support and urethral closure pressure. J Urol 2008; 179: 2286-2290; discussion 2290

[4] Dietz HP, Clarke B, Herbison P. Bladder neck mobility and urethral closure pressure as predictors of genuine stress incontinence. Int Urogynecol J Pelvic Floor Dysfunct 2002; 13: 289-293

[5] Thompson JA, O'Sullivan PB, Briffa NK et al. Assessment of voluntary pelvic floor muscle contraction in continent and incontinent women using transperineal ultrasound, manual muscle testing and vaginal squeeze pressure measurements. Int Urogynecol J Pelvic Floor Dysfunct 2006; 17: $624-630$

[6] Peschers U, Schaer G, Anthuber C et al. Changes in vesical neck mobility following vaginal delivery. Obstet Gynecol 1996; 88: 1001-1006

[7] Thompson JA, O'Sullivan PB, Briffa NK et al. Comparison of transperineal and transabdominal ultrasound in the assessment of voluntary pelvic floor muscle contractions and functional manoeuvres in continent and incontinent women. Int Urogynecol J Pelvic Floor Dysfunct 2007; 18: 779-786

[8] van Delft K, Thakar R, Sultan AH. Pelvic floor muscle contractility: digital assessment vs. transperineal ultrasound. Ultrasound Obstet Gynecol 2015; 45: 217-222

[9] Howard D, Miller JM, Delancey JO et al. Differential effects of cough, valsalva, and continence status on vesical neck movement. Obstet Gynecol 2000; 95: 535-540

[10] Schaer GN, Koechli OR, Schuessler B et al. Perineal ultrasound: determination of reliable examination procedures. Ultrasound Obstet Gynecol 1996; 7: 347-352

[11] Miller JM, Ashton-Miller JA, DeLancey JO. A pelvic muscle precontraction can reduce cough-related urine loss in selected women with mild SUI. J Am Geriatr Soc 1998; 46: 870-874

[12] Miller JM, Perucchini D, Carchidi LT et al. Pelvic floor muscle contraction during a cough and decreased vesical neck mobility. Obstet Gynecol 2001; 97: 255-260

[13] Junginger B, Seibt E, Baessler K. Bladder-neck effective, integrative pelvic floor rehabilitation program: follow-up investigation. Eur J Obstet Gynecol Reprod Biol 2014; 174: 150-153

[14] Braekken IH, Majida M, Engh ME et al. Can pelvic floor muscle training reverse pelvic organ prolapse and reduce prolapse symptoms? An assessor-blinded, randomized, controlled trial. Am J Obstet Gynecol 2010; 203: 170.e1-170.e7

[15] Bo K, Stien R. Needle EMG registration of striated urethral wall and pelvic floor muscle activity patterns during cough, Valsalva, abdominal, hip adductor, and gluteal muscle contractions in nulliparous healthy females. Neurourol Urodyn 1994; 13: 35-41

[16] Hodges PW, Richardson CA. Inefficient muscular stabilization of the lumbar spine associated with low back pain. A motor control evaluation of transversus abdominis. Spine (Phila Pa 1976) 1996; 21: 2640-2650

[17] Sapsford RR, Hodges PW, Richardson CA et al. Co-activation of the abdominal and pelvic floor muscles during voluntary exercises. Neurourol Urodyn 2001; 20: 31-42

[18] Smith MD, Coppieters MW, Hodges PW. Postural response of the pelvic floor and abdominal muscles in women with and without incontinence. Neurourol Urodyn 2007; 26: 377-385
[19] Smith MD, Coppieters MW, Hodges PW. Postural activity of the pelvic floor muscles is delayed during rapid arm movements in women with stress urinary incontinence. Int Urogynecol J Pelvic Floor Dysfunct 2007; 18: 901-911

[20] Junginger B, Baessler K, Sapsford R et al. Effect of abdominal and pelvic floor tasks on muscle activity, abdominal pressure and bladder neck. Int Urogynecol J 2010; 21: 69-77

[21] Baessler K, Junginger $B$. Why do women leak urine? Which continence mechanism(s) fail(s)? Int Urogynecol J 2013; 24: 90-91

[22] Fischer W, Baessler K. Postpartum pelvic floor conditioning using vaginal cones: not only for prophylaxis against urinary incontinence and descensus. Int Urogynecol J Pelvic Floor Dysfunct 1996; 7: 208-214

[23] Thompson JA, O'Sullivan PB. Levator plate movement during voluntary pelvic floor muscle contraction in subjects with incontinence and prolapse: a cross-sectional study and review. Int Urogynecol J Pelvic Floor Dysfunct 2003; 14: 84-88

[24] Amaro JL, Moreira EC, De Oliveira Orsi Gameiro M et al. Pelvic floor muscle evaluation in incontinent patients. Int Urogynecol J Pelvic Floor Dysfunct 2005; 16: 352-354

[25] Baessler K, Kempkensteffen C. [Validation of a comprehensive pelvic floor questionnaire for the hospital, private practice and research]. Gynakol Geburtshilfliche Rundsch 2009; 49: 299-307

[26] Dietz HP, Bennett M]. The effect of childbirth on pelvic organ mobility. Obstet Gynecol 2003; 102: 223-228

[27] Dietz HP, Lanzarone V. Levator trauma after vaginal delivery. Obstet Gynecol 2005; 106: 707-712

[28] Reddy AP, DeLancey JO, Zwica LM et al. On-screen vector-based ultrasound assessment of vesical neck movement. Am J Obstet Gynecol 2001: 185: 65-70

[29] Dietz HP. Ultrasound imaging of the pelvic floor. Part I: two-dimensional aspects. Ultrasound Obstet Gynecol 2004; 23: 80-92

[30] Schaer GN, Koechli OR, Schuessler B et al. Perineal ultrasound for evaluating the bladder neck in urinary stress incontinence. Obstet Gynecol 1995; 85: 220-224

[31] Bo K. Pelvic floor muscle exercise for the treatment of stress urinary incontinence: an exercise physiology perspective. Int Urogynecol J 1995; 6: 282-291

[32] Bo K, Kvarstein B, Nygaard I. Lower urinary tract symptoms and pelvic floor muscle exercise adherence after 15 years. Obstet Gynecol 2005; 105: 999-1005

[33] Hides JA, Jull GA, Richardson CA. Long-term effects of specific stabilizing exercises for first-episode low back pain. Spine (Phila Pa 1976) 2001; 26 : E243-E248

[34] Delancey JO. Why do women have stress urinary incontinence? Neurourol Urodyn 2010; 29 (Suppl. 1): S13-S17

[35] Howard D, Miller JM, Delancey JO et al. Differential effects of cough, valsalva, and continence status on vesical neck movement. Obstet Gynecol 2000; 95: 535-540

[36] Dietz HP, Wilson PD, Clarke B. The use of perineal ultrasound to quantify levator activity and teach pelvic floor muscle exercises. Int Urogynecol J Pelvic Floor Dysfunct 2001; 12: 166-168; discussion 168-169

[37] de Jong TP, Klijn AJ, Vijverberg MA et al. Effect of biofeedback training on paradoxical pelvic floor movement in children with dysfunctional voiding. Urology 2007; 70: 790-793

[38] Jedrzejczak A, Chipchase LS. The availability and usage frequency of real time ultrasound by physiotherapists in South Australia: an observational study. Physiother Res Int 2008; 13: 231-240 